\title{
First Experience with Cryo-Balloon Ablation of Atrial Fibrillation. A Case Report
}

\author{
Samir Rafla*, Ahmed Mokhtar, Eman El Sharkawy, Tarek El Zawawy and Moustafa Nawar \\ Faculty of Medicine, Alexandria University, Egypt
}

Submission: April 23, 2019; Published: May 24, 2019

*Corresponding author: Samir Rafla, Faculty of Medicine, Alexandria University, Egypt

Abstract

We compared the efficacy and safety of radiofrequency with cryothermal energy in catheter ablation of patients with paroxysmal AF. The study included 24 consecutive patients with highly symptomatic paroxysmal AF (PAF) refractory to at least 1 class of antiarrhythmic drugs. Group I radiofrequency ablation and group II cryoballoon ablation (each group consists of 12 patients). Exclusion criteria: Patients $<18$ years, Structural heart disease (hypertrophic cardiomyopathy, left ventricular ejection fraction $<35 \%$, significant valvular heart disease, LA size $>50$ $\mathrm{mm}$ ), reversible causes of $\mathrm{AF}$, intracardiac thrombus, inability to take oral anticoagulants, additional ablation lines other than cavotricuspid isthmus (CTI) and Repeat AF ablation. Transseptal puncture was performed under fluoroscopic guidance, one for the cryoballoon and two for the RF ablation.

Results: The two groups were matched regarding the demographic data and pre-procedural risk factors. PVI was successfully achieved in all cases; there was a significant difference in procedure duration and fluoroscopy time between the two groups. Mean procedural time for the RF group was $171.2 \pm 17.4 \mathrm{~min}$ and it was significantly longer than the CB group in which the mean procedure time was $127.9 \pm 23.5 \mathrm{~min}(\mathrm{P}>0.001$ ). Regarding the fluoroscopy time, it was significantly longer in the RF group compared to the CB group $(61.42 \pm 17.6 \mathrm{~min}$ vs. $45.7 \pm 9.8 \mathrm{~min}$, $\mathrm{P}=0.014)$. Regarding the efficacy defined as freedom from Atrial fibrillation and atrial tachycardia lasting more than 30 secs after the blanking period, 3 cases $25 \%$ had recurrence in the form of AF in two cases and $\mathrm{AT}$ in one case in the RF group, while in the $\mathrm{CB}$ group one case $8.3 \%$ have recurrence in the form of $\mathrm{AF}$ (P not significant). Regarding to the safety, transient Phrenic nerve palsy (PNP) occurred in one case (8.3\%) in the $\mathrm{CB}$ group compared to $0 \%$ in the RF group. Symptomatic PV stenosis occurred in one case (8.3\%) in the RF group compared to $0 \%$ in the CB group. Vascular access complications in the form of hematoma not requiring blood transfusion or intervention were the same in both groups, $16.7 \%$ of cases in each group- $(\mathrm{P}=1.00)$, no major vascular complication occurred. Among the 4 cases with recurrence of AF and AT, the most important predictors of recurrence were LA dimension and AF duration before the procedure.

Conclusion: Radiofrequency ablation and cryoballoon are effective in treating paroxysmal AF with similar success rate and similar safety profile. Cryoballoon is a good alternative that has a short learning curve and can result in more standardized results. Cryoballoon significantly reduces the $\mathrm{AF}$ ablation procedure time and radiation exposure. Longer $\mathrm{AF}$ durations and larger atrial dimensions are strong predictors of $\mathrm{AF}$ recurrence regardless the ablation source used.

Keywords: AF ablation; Cryoballoon; Radiofrequency ablation

\section{Introduction}

Atrial fibrillation (AF), the most common form of cardiac arrhythmia, is associated with a risk of associated complications such as stroke and heart failure, in addition to a higher rate of mortality [1]. The economic burden of AF is expected to increase dramatically [2].

The pathophysiology of AF is complex and multifactorial. Triggers from inside the pulmonary veins (PV) are accepted as source of paroxysmal AF [3]. Pulmonary vein isolation (PVI) represents the basis of catheter ablation of paroxysmal AF [1]. Catheter ablation of $\mathrm{AF}$ is recommended for symptomatic improvement in patients with recurrent highly symptomatic drug refractory paroxysmal AF when done by experienced operators [1-3]. The aim is to have complete durable transmural isolation ablation line.

Radiofrequency (RF) and cryo-energy are the most commonly used energy sources for AF ablation [1]. RF results in ablation by conduction of alternating electric current into the tissues resulting in its dissipation as heat. This heating will cause coagulative necrosis of the tissues and fibrous tissue formation [1]. Cryothermal energy is an alternative energy source. The 
mechanism of tissue injury originates from tissue freezing with ice crystals formation inside the cell causing cell membranes disruption and cell death [1]. Several trials have compared both technologies in ablation of paroxysmal and persistent forms of $\mathrm{AF}$ with comparable efficacy and safety results.

The aim of the current study was to compare the two source of energy in patient with paroxysmal $\mathrm{AF}$ as an initial experience in $\mathrm{AF}$ ablation in the electrophysiology unit, cardiology and angiology department, Alexandria University.

\section{Materials and Methodology}

The study included 24 consecutive patients with highly symptomatic paroxysmal AF (PAF) refractory to at least 1 class of antiarrhythmic drugs, referred for catheter ablation in the electrophysiology unit, department of cardiology and angiology, Alexandria university hospital.

They were assigned into either of the following two groups: group I for radiofrequency ablation and group II for cryoballoon ablation (each group consists of 12 patients). Patients were eligible for the study if they were able and willing to give written, informed consent, had a history of symptomatic paroxysmal AF, were refractory to at least 1 of class I or III antiarrhythmic drug and were undergoing a first PVI procedure.

\section{Exclusion criteria}

Patients $<18$ years, Structural heart disease (hypertrophic cardiomyopathy, left ventricular ejection fraction $<35 \%$, significant valvular heart disease, LA size $>50 \mathrm{~mm}$ ), reversible causes of $\mathrm{AF}$, intracardiac thrombus, inability to take oral anticoagulants, additional ablation lines other than cavotricuspid isthmus (CTI) and Repeat AF ablation.

Preprocedural: All patients were subjected to History taking, clinical examination, electrocardiographic evaluation, transthoracic echocardiographic evaluation and transesophageal echocardiographic (TEE) evaluation.

\section{PVI procedure}

Procedures were performed under mild sedation or general anaesthesia. Deflectable decapolar catheter was placed in the coronary sinus (CS) through transfemoral venous access. Transseptal puncture was performed under fluoroscopic guidance, one for the cryoballoon and two for the RF ablation. A bolus of unfractionated heparin 70IU/kg followed by continous IV infusion to maintain activated clotting time (ACT) more than $300 \mathrm{~s}$.

Group I (RF ablation): Circular mapping catheter was placed sequentially within each of the $4 \mathrm{PV}$ antra to record baseline electric activity (PV potentials). Irrigated $3.5 \mathrm{~mm}$ tip mapping and ablation catheter (Ezsteer or Smart touch catheter, Biosense Webster) was used to create wide antral circumferential RF ablations across ipsilateral PVs without additional LA ablation lines (Figure 1). Assessment of PVI using circular mapping catheter was checked 20 minutes after ablation with pacing maneuver to confirm exit and entrance block.

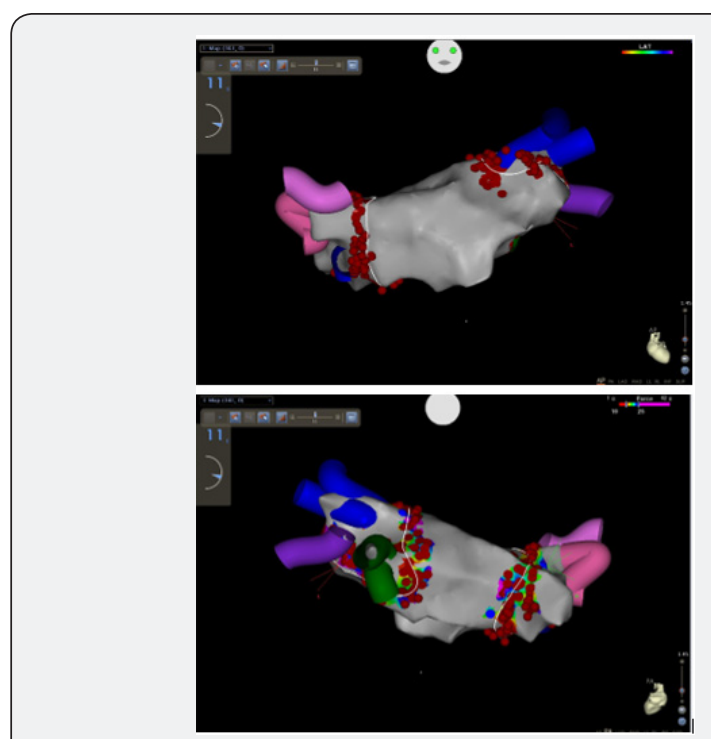

Figure 1: Example of a case of PVI using $3 \mathrm{D}$ anatomical mapping system and smart touch RF catheter: upper panel anteroposterior (AP) view, lower panel posteroanterior (PA) view.
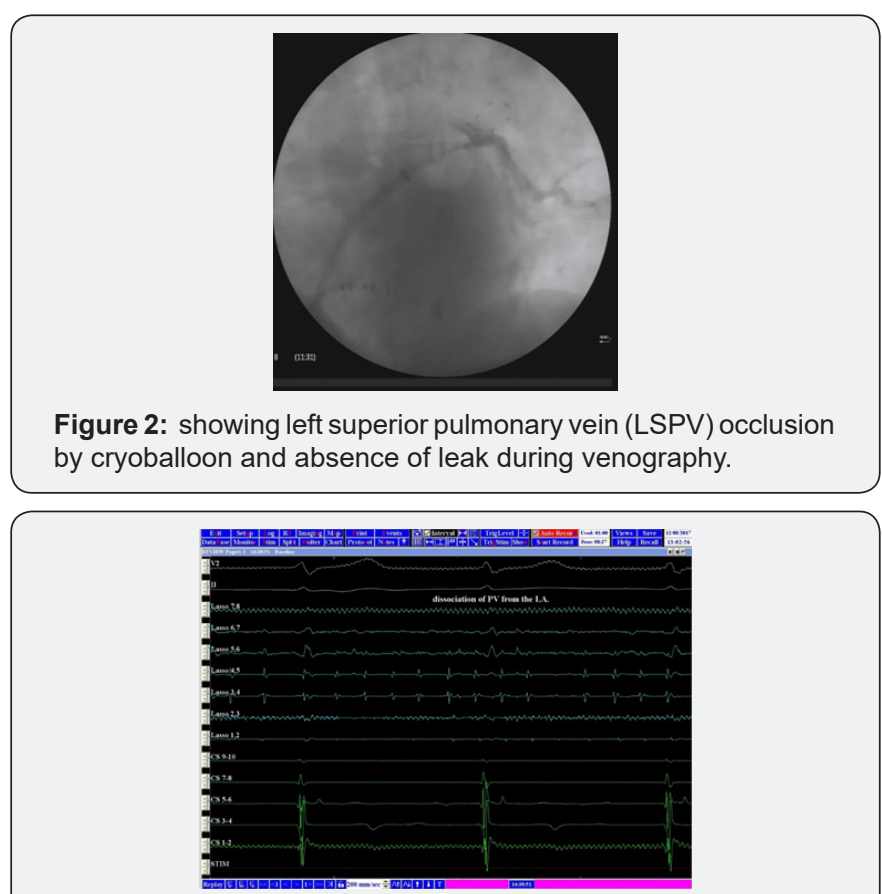

Figure 3: Example of dissociated PV from the LA, fibrillatory waves seen in the Lasso catheter while CS catheter shows sinus rhythm.

Group II (cryoballoon CB ablation): Flex Cath sheath was advanced into the LA through the traansseptal puncture. Second generation cryoballoon catheter was introduced through the sheath, inflated and advanced to the ostium of each PV. Assessment of complete PV occlusion using venous angiogram and confirmed by absence of leak (Figure 2). Freezing was applied in each vein to reach a temperature less than $-400 \mathrm{C}$ and continued for at least 
120 msec from the documented PV isolation time. Monitoring of phrenic nerve palsy during ablation of right PV was done by pacing of the right phrenic nerve using quadripolar catheter in the superior vena cava. Assessment of PVI using Achieve circular mapping catheter and was checked 20 minutes after ablation (Figure $3 \& 4$ ).

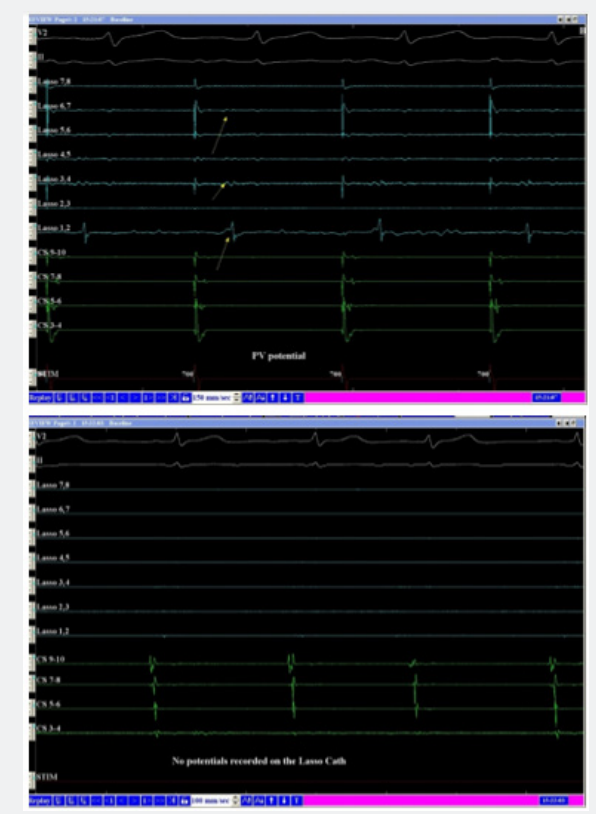

Figure 4: Loss of PV potential with ablation. Upper panel before ablation with PV potential, lower panel after ablation with no PV potential.

Postablation Follow-Up and Outcomes: All patients were discharged home next day after the procedure. Patients continued anticoagulation with NOAC or warfarin for a minimum of 3 months. Further anticoagulation was decided according to the individual patient CHA2DS2 VASC score. Antiarrhythmic medications (class I or class III AADs) were continued for 3 months post ablation. Patients were followed up in the outpatient clinic with clinical, 12-lead ECG and 24-h Holter monitoring at 3- and 6-months post ablation and upon symptomatic events. The procedure end point was PV isolation confirmed with entrance and exit block. The short and intermediate term efficacy was the freedom from AF or atrial flutter/tachycardia lasting more than 30 secs in the absence of antiarrhythmic drug therapy. A blanking period of 3 months after the initial ablation was used during which any tachycardia occurrence was noted counted as recurrence. The safety endpoints were comparison of significant adverse effects between the two groups.

\section{Statistical Methods}

Data were analyzed using the Statistical Package for Social Sciences (SPSS ver.20 Chicago, IL, USA). Quantitative data were described using mean, standard deviation. Qualitative data were described using number and percent. Comparing quantitative normally distributed variables between 2 groups was done using Independent samples $\mathrm{t}$ test, and Mann Whitney $\mathrm{U}$ test was used for non-parametric data. Pearson Chi square used to compare 2 $\times 2$ categorical variables, and Fisher's Exact test when if $>20 \%$ of cells had expected cell count less than 5 . And in $>2 \times 2$ table we used Monte Carlo significance test if $>20 \%$ of cells had expected cell count less than 5 . In all statistical tests, level of significance of .05 used, below which the results considered to be statistically significant.

\section{Results}

The two groups were matched regarding the demographic data and pre-procedural risk factors. Table 1 shows demographic data of the patients and preoperative risk factors.

Table 1: Demographic data and preprocedural characteristics.

\begin{tabular}{|c|c|c|c|c|}
\hline \multicolumn{2}{|c|}{ Parameter } & RF group ( $N=12)$ & CB group $(\mathrm{N}=12)$ & Test and $P$ value \\
\hline \multicolumn{2}{|c|}{ Age in years (Mean \pm SD) } & $48.42 \pm 12.717$ & $53.50 \pm 8.909$ & $\mathrm{t}=1.134 \mathrm{P}=0.269$ \\
\hline \multirow{2}{*}{ Sex } & Male & $6(50 \%)$ & $8(66.7 \%)$ & \multirow{2}{*}{$\mathrm{X}^{2}=0.686 \mathrm{P}=0.408$} \\
\hline & Female & $6(50 \%)$ & $4(33.3 \%)$ & \\
\hline \multicolumn{2}{|c|}{ Hypertension } & $6(50 \%)$ & $9(75 \%)$ & $\mathrm{FEP}=0.400$ \\
\hline \multicolumn{2}{|c|}{ DM } & $1(8.3 \%)$ & $5(41.7 \%)$ & $\mathrm{FEP}=0.155$ \\
\hline \multicolumn{2}{|c|}{ Thyroid disease } & $2(16.7 \%)$ & $1(8.3 \%)$ & $\mathrm{FEP}=1.00$ \\
\hline \multicolumn{2}{|c|}{ Renal disease } & $0(0.0 \%)$ & $0(0.0 \%)$ & \\
\hline \multicolumn{2}{|c|}{ COPD } & $2(16.7 \%)$ & $3(25 \%)$ & $\mathrm{FEP}=1.00$ \\
\hline \multicolumn{2}{|c|}{ Previous TIA or Stroke } & $0(0.0 \%)$ & $1(8.3 \%)$ & $\mathrm{FEP}=1.00$ \\
\hline \multicolumn{2}{|c|}{ Structural heart disease } & $4(33.3 \%)$ & $1(8.3 \%)$ & $\mathrm{FEP}=0.317$ \\
\hline \multicolumn{2}{|c|}{ AF duration in years $($ Mean \pm SD) } & $4.75 \pm 3.019$ & $6.25 \pm 4.003$ & $\mathrm{t}=1.036 \mathrm{P}=0.311$ \\
\hline \multicolumn{2}{|c|}{ LA dimension in $\mathrm{mm}($ Mean \pm SD $)$} & $44.25 \pm 4.957$ & $41.75 \pm 4.475$ & $\mathrm{t}=-1.297-\mathrm{P}=0.208$ \\
\hline \multicolumn{2}{|c|}{$\mathrm{EF}($ Mean $\pm \mathrm{SD})$} & $63.67 \pm 5.758$ & $66.25 \pm 4.351$ & $\mathrm{t}=1.240 \mathrm{P}=0.229$ \\
\hline \multicolumn{2}{|c|}{$\mathrm{CHA}_{2} \mathrm{DS}_{2} \mathrm{VASc}$ (median) } & 1 & 1.5 & $\begin{array}{c}\text { Mann-Whitney U } \\
\mathrm{P}=0.441\end{array}$ \\
\hline \multicolumn{2}{|c|}{ Anticoagulation } & & & \\
\hline
\end{tabular}




\begin{tabular}{|c|c|c|c|}
\hline Vit $\mathrm{K}$ antagonist & $6(50 \%)$ & $3(25 \%)$ & \multirow{4}{*}{$\mathrm{MCP}=0.055$} \\
\hline NOAC & $1(8.3 \%)$ & $5(41.7 \%)$ & \\
\hline None & $5(41.7 \%)$ & $2(16.7 \%)$ & \\
\hline Antiplatelet & $0(0.0 \%)$ & $2(16.7 \%)$ & \\
\hline
\end{tabular}

PVI was successfully achieved in all cases; there was a significant difference in procedure duration and fluoroscopy time between the two groups. Mean procedural time for the RF group was $171.25 \pm 17.468 \mathrm{~min}$ and it was significantly longer than the CB group in which the mean procedure time was $127.92 \pm$ 23.593 min $(P>0.001)$. Regarding the fluoroscopy time, it was significantly longer in the RF group compared to the $\mathrm{CB}$ group (61.42 \pm 17.625 min vs. $45.75 \pm 9.891 \mathrm{~min}, \mathrm{P}=0.014)$.

Regarding the efficacy defined as freedom from Atrial fibrillation and atrial tachycardia lasting more than 30 secs after the blanking period, 3 cases $25 \%$ had recurrence in the form of $\mathrm{AF}$ in two cases and AT in one case in the RF group, while in the CB

Table 2: Complications related to the procedure.

\begin{tabular}{|c|c|c|c|}
\hline Parameter & RF group (N=12) & CB group (N=12) & Test and P value \\
\hline Vascular complications & $2(16.7 \%)$ & $2(16.7 \%)$ & FEP=1.00 \\
\hline Pulmonary stenosis & $1(8.3 \%)$ & $0(0.0 \%)$ & FEP=1.00 \\
\hline Phrenic nerve palsy (PNP) & $0(0.0 \%)$ & $1(8.3 \%)$ & FEP=1.00 \\
\hline GIT symptoms & $2(16.7 \%)$ & $0(0.0 \%)$ & FEP=0.478 \\
\hline TIA\& stroke & $0(0.0 \%)$ & $0(0.0 \%)$ & $0(0.0 \%)$ \\
\hline AE Fistula & $0(0.0 \%)$ & $0(0.0 \%)$ & \\
\hline Pericardial effusion & $0(0.0 \%)$ & $0(0.0 \%)$ & \\
\hline MI & $0(0.0 \%)$ & $0(0.0 \%)$ & \\
\hline Air embolism & $0(0.0 \%)$ & $0(0.0 \%)$ & \\
\hline Death & $0(0.0 \%)$ & & \\
\hline
\end{tabular}

Table 3: Significant predictors of AF recurrence.

\begin{tabular}{|c|c|c|c|}
\hline Parameter & AF recurrence & No recurrence & $P$ value \\
\hline \multicolumn{4}{|c|}{ LA dimension } \\
\hline Median & 49.00 & 42.00 & \multirow{4}{*}{$\begin{array}{c}\text { Mann-Whitney U } \\
\mathrm{P}=0.020\end{array}$} \\
\hline Minimum & 45 & 35 & \\
\hline Maximum & 50 & 50 & \\
\hline Mean \pm SD & $48.25 \pm 2.217$ & $41.95 \pm 4.478$ & \\
\hline \multicolumn{4}{|l|}{ AF duration } \\
\hline Median & 9.50 & 4.00 & \multirow{4}{*}{$\begin{array}{c}\text { Mann-Whitney U } \\
P=0.007\end{array}$} \\
\hline Minimum & 8 & 1 & \\
\hline Maximum & 16 & 10 & \\
\hline Mean \pm SD & $10.75 \pm 3.594$ & $4.45 \pm 2.502$ & \\
\hline
\end{tabular}

Among the 4 cases with recurrence of AF and AT, the most important predictors of recurrence were LA dimension and $\mathrm{AF}$ duration before the procedure (Table 3 ). The mean left atrial dimension associated with AF recurrence was 48.25 \pm 2.217 $\mathrm{mm}$ compared to $41.95 \pm 4.478 \mathrm{~mm}$ in those who remained in sinus rhythm, $\mathrm{P}$ value $=0.020$. AF duration longer than 10 years was strongly associated with $\mathrm{AF}$ recurrence, mean duration in group one case $8.3 \%$ have recurrence in the form of $\mathrm{AF}$ and this was statistically insignificant $(\mathrm{P}=0.590)$.

Regarding to the safety end points, Table 2 describes the important procedure related complications. Transient Phrenic nerve palsy (PNP) occurred in one case (8.3\%) in the CB group compared to $0 \%$ in the RF group, $(\mathrm{P}=1)$. Symptomatic $\mathrm{PV}$ stenosis occurred in one case (8.3\%) in the RF group compared to $0 \%$ in the $\mathrm{CB}$ group, $(\mathrm{P}=1)$. Vascular access complications in the form of hematoma not requiring blood transfusion or intervention were the same in both groups, $16.7 \%$ of cases in each group- $(\mathrm{P}=1.00)$, no major vascular complication occurred. cases with AF recurrence was $10.75 \pm 3.594$ years compared to $4.45 \pm 2.502$ years in case with sinus rhythm, $P$ value $=0.007$.

\section{Discussion}

In this study, 24 cases of paroxysmal AF refractory to medical treatment were non-randomly assigned to either $\mathrm{RF}$ or $\mathrm{CB}$ ablation of AF. Both ablation technologies were equal regarding 
the safety and efficacy with insignificant difference in incidence of AF and AT. Freedom from AF and AT was $75 \%$ and $91.7 \%$ in the RF and CB groups respectively with no statistical significance. These data are consistent with a lot of data from previous trials and meta-analysis.

In our study, there was a significant difference between both technologies regarding the procedure duration and fluoroscopy time. This could be explained by the more rapid single application of the balloon compared to point by point energy application in the RF technology. Another important cause for shorter duration is the easier learning curve required for the cryoballoon that leads to rapid acquisition of the skills and more standardized results. In the contrary, RF AF ablation needs more sophisticated technical skills and more cumulative learning experience that usually acquired with larger number of procedures and longer training periods to be familiar with the 3-D anatomical mapping system and quicker in effective durable ablation line formation.

In Wasserlauf et al. [4], procedure times were shorter with CBA $(192.9 \pm 44.0$ minutes vs $283.7 \pm 78.0$ minutes in the RFA, $P$ $<0.001)$.

In Aryana et al. [5], CB ablation was associated with shorter procedure time $(145 \pm 49$ minutes vs. $188 \pm 42$ minutes in the RFA, $\mathrm{P}<0.001)$.

In the FIRE AND ICE trial Kuck KH [6], the mean total procedure time was shorter in the cryoballoon group than in the radiofrequency group (124 vs. 141 minutes, $\mathrm{P}<0.001$ ), as was the left atrial dwell time (the length of time the catheter was present in the left atrium during the procedure) (92 vs. 109 minutes, $\mathrm{P}<0.001$ ).

In Hunter et al [7], Procedure time was 211 minutes for RFCA compared to 167 minutes for CRYO and 278 minutes for COMBINED $(\mathrm{P}<0.001)$.

In the Meta-analysis by Cardoso et al. [8], procedural time was significantly lower among patients who underwent CB ablation ( $\mathrm{P}$ $<0.01)$.

Chen et al. [9] found that compared with non-CF-RF, CB1 and $\mathrm{CB} 2$ both showed a significant reduction in procedural time, while when comparing $\mathrm{CB}$ with CF-RF no statistically significant difference was found in procedural time.

In contrast, Jourda et al. [10] found that the duration of the procedure was significantly lower in the $\mathrm{CF}$ group compared to CB2 $(110.7+32.5$ vs. $134.5+48.3 \mathrm{~min}, \mathrm{P}>0.001)$.

When it comes to the fluoroscopy time, a large heterogeneity was found among the published data. Some authors reported shorter duration in the RF compared to CB. Others reported shorter duration with the $\mathrm{CB}$. We think that the cause of the variability of the fluoroscopy time is strongly related to operator's experience in both systems. In other words, we think that those who are expert in 3-D anatomical mapping systems rely more on the 3-D map rather than the Fluoroscopy. Operators who are in the early steps of 3-D anatomical mapping training tend to rely more on the Fluoroscopy.

In the view of the rapid learning curve in the CB compared to $\mathrm{RF}$, we expect operators that initiate both technologies in the same time will have shorter fluoroscopy time in the CB procedures. The reverse is expected in those with previous experience in the RF systems before initiating CB program.

In our study, the fluoroscopy time was significantly longer in the RF group compared to the CB group $(61.42 \pm 17.625$ min vs. $45.75 \pm 9.891 \mathrm{~min}, \mathrm{P}=0.014)$. We think that this is linked to our primitive steps in the RF AF ablation program.

In Wasserlauf et al. [4] total fluoroscopy times were shorter in the CBA compared to RFA $(46.0 \pm 22.4$ minutes vs $73.0 \pm 30.1$ minutes, $\mathrm{P}<0.001)$. They stated that the main findings of this study were that an early experience with CBA for AF was associated with decreased procedure and fluoroscopy times compared to RFA. Of note, although operators were early in their experience with CBA and already experienced with RFA, CBA was still associated with shorter procedure and fluoroscopy times.

In a meta-analysis by Junxia et al. [11] the overall analyses indicated that cryoballoon ablation significantly reduced fluoroscopic time and total procedure time by a weighted mean of $14.13(\mathrm{P}=0.014)$ minutes and $29.65(\mathrm{P}=0.006)$ minutes compared with radiofrequency ablation, respectively.

On the other hand, Aryana et al. [5] found that CB was associated with greater fluoroscopic utilization compared to RFA $(29 \pm 13$ minutes vs. $23 \pm 14$ minutes; $\mathrm{P}<0.001)$.

Jourda et al. [10] found that CF-RF was associated with a lower duration of fluoroscopy compared to CB $(21.5+8.5$ vs. $25.3+$ $9.9 \min , \mathrm{P}=0.017$ ).

In the FIRE AND ICE trial, the mean total fluoroscopy time was shorter in the radiofrequency group than in the cryoballoon group (17 vs. 22 minutes, $\mathrm{P}<0.001$ ).

Other data suggest that there is no significant difference in the fluoroscopy duration between both technologies. In the FreezeAF trial [12], the $x$-ray duration was very similar in both groups (median, 24 minutes in $\mathrm{RF}$ and 25.5 minutes in $\mathrm{CB}$; $\mathrm{P}=0.632$ ). In the meta-analysis done by Cardoso et al. [8] fluoroscopy duration was not significantly different between both groups. In a metaanalysis by Chen et al. [9] there was no statistically significant difference in the fluoroscopy duration between CF-RF and CB2. In the meta-analysis done by Buiatti et al. [13], Ablation procedures performed with CB vs. RF displayed a comparable fluoroscopy duration (range 17 - 61 min vs. 18 - 73 min; $\mathrm{P}=0.60$ ). There was a high heterogeneity for this risk estimate.

In the current study, AF recurrence was strongly associated with longer $\mathrm{AF}$ duration and larger left atrial dimension. The mean left atrial dimension associated with AF recurrence was 
$48.25 \pm 2.217 \mathrm{~mm}$ compared to $41.95 \pm 4.478 \mathrm{~mm}$ in those who remained in sinus rhythm, $\mathrm{P}$ value $=0.020$. regarding $\mathrm{AF}$ duration, the mean duration in cases with $\mathrm{AF}$ recurrence was $10.75 \pm 3.594$ years compared to $4.45 \pm 2.502$ years in case with sinus rhythm, $\mathrm{P}$ value $=0.007$.

These findings are consistent with data from Quan et al. [14]. Quan et al. [14] published a meta-analysis titled " Predictors of late atrial fibrillation recurrence after cryoballoon-based pulmonary vein isolation: a meta-analysis". They found that early recurrence in the blanking period, increased left atrial size, a long duration of $\mathrm{AF}$ before ablation and persistent $\mathrm{AF}$ are independent predictors of late recurrence after cryoballoon ablation.

\section{Conclusion}

From the present study, we concluded that:

1. Radiofrequency ablation and cryoballoon are effective in treating paroxysmal AF with similar success rate and similar safety profile.

2. Cryoballoon is a good alternative that has a short learning curve and can result in more standardized results.

3. Cryoballoon significantly reduces the AF ablation procedure time.

4. Longer AF durations and larger atrial dimensions are strong predictors of AF recurrence regardless the ablation source used.

\section{Conflict of Interest: Nothing to display.}

\section{References}

1. Calkins H, Kuck KH, Cappato R, Brugada J, Camm AJ, et al. (2012) HRS/ EHRA/ECAS expert consensus statement on catheter and surgical ablation of atrial fibrillation: recommendations for patient selection, procedural techniques, patient management and follow-up, definitions, endpoints, and research trial design. Heart Rhythm 9(4): 632-696. e21.

2. January CT, Wann LS, Alpert JS, Calkins H, Cigarroa JE, et al. (2014) AHA/ACC/HRS Guideline for the Management of Patients with Atrial Fibrillation. A Report of the American College of Cardiology/American Heart Association Task Force on Practice Guidelines and the Heart Rhythm Society. J Am Coll Cardiol 64(21): e1-e76.

3. Kirchhof P, Benussi S, Kotecha D, Ahlsson A, Atar D, et al. (2016) ESC Guidelines for the management of atrial fibrillation developed in collaboration with EACTS. The Task Force for the management of atrial fibrillation of the European Society of Cardiology (ESC). Eur Heart J 37(38): 2893-2962.

4. Wasserlauf J, Pelchovitz DJ, Rhyner J, Verma N, Bohn M, et al. (2015) Cryoballoon versus Radiofrequency Catheter Ablation for Paroxysmal Atrial Fibrillation. Pacing Clin Electrophysiol 38(4): 483-489.

5. Aryana A, Singh S, Kowalski M, Pujara DK, Cohen AI, et al. (2015) Acute and Long-Term Outcomes of Catheter Ablation of Atrial Fibrillation Using the Second-Generation Cryoballoon versus Open-Irrigated Radiofrequency: A Multicenter Experience. J Cardiovasc Electrophysiol 26(8): 832-839.

6. Kuck KH, Brugada J, Fürnkranz A, Metzner A, Ouyang F, et al. (2016) Cryoballoon or Radiofrequency Ablation for Paroxysmal Atrial Fibrillation. FIRE AND ICE trial. N Engl J Med 374(23): 2235-2245.

7. Hunter RJ, Baker V, Finlay MC, Duncan ER, Lovell MJ, et al. (2015) Pointby-Point Radiofrequency Ablation Versus the Cryoballoon or a Novel Combined Approach: A Randomized Trial Comparing 3 Methods of Pulmonary Vein Isolation for Paroxysmal Atrial Fibrillation (The Cryo Versus RF Trial). J Cardiovasc Electrophysiol 26(12): 1307-1314.

8. Cardoso R, Mendirichaga R, Fernandes G, Healy C, Lambrakos LK, et al (2016) Cryoballoon versus Radiofrequency Catheter Ablation in Atrial Fibrillation: A Meta-Analysis. J Cardiovasc Electrophysiol 27(10): 1151-1159.

9. Chen CF, Gao XF, Duan X, Chen B, Liu XH, et al. (2017) Comparison of catheter ablation for paroxysmal atrial fibrillation between cryoballoon and radiofrequency: a meta-analysis. J Interv Card Electrophysiol 48(3): 351-366.

10. Jourda F, Providencia R, Marijon E, Bouzeman A, Hireche H, et al. (2015) Contact-force guided radiofrequency vs. second generation balloon cryotherapy for pulmonary vein isolation in patients with paroxysmal atrial fibrillation-a prospective evaluation. Europace 17(2): 225-231.

11.Xu J, Huang y, Cai H, Qi Y, Jia N, et al. (2014) Is Cryoballoon Ablation Preferable to Radiofrequency Ablation for Treatment of Atrial Fibrillation by Pulmonary Vein Isolation? A Meta-Analysis. PLoS ONE 9(2): e90323.

12. Luik A, Radzewitz A, Kieser M, Walter M, Bramlage P, et al. (2015) Cryoballoon Versus Open Irrigated Radiofrequency Ablation in Patients with Paroxysmal Atrial Fibrillation. The Prospective, Randomized, Controlled, Noninferiority FreezeAF Study. Circulation 132(14): 13111319.

13. Buiatti A, Olshausen G, Barthel P, Schneider S, Luik A, et al. (2017) Cryoballoon vs. radiofrequency ablation for paroxysmal atrial fibrillation: an updated metaanalysis of randomized and observational studies. Europace 19(3): 378-384.

14. Quan D, Huang H, Kong B, Li Q, Liao J, et al. (2017) Predictors of late atrial fibrillation recurrence after cryoballoon-based pulmonary vein isolation: a meta-analysis. Kardiologia Polska 75(4): 376-385.

\begin{tabular}{l} 
Your next submission with Juniper Publishers \\
will reach you the below assets \\
- Quality Editorial service \\
- Swift Peer Review \\
- Reprints availability \\
- E-prints Service \\
- Manuscript Podcast for convenient understanding \\
- Global attainment for your research \\
- Manuscript accessibility in different formats \\
( Pdf, E-pub, Full Text, Audio) \\
- Unceasing customer service \\
Track the below URL for one-step submission \\
https://juniperpublishers.com/online-submission.php \\
\hline
\end{tabular}

